\title{
Representação social da indisciplina escolar
}

\author{
Adriano Charles Ferreira ${ }^{1}$ \\ Edvanderson Ramalho dos Santos \\ Ademir José Rosso \\ Universidade Estadual de Ponta Grossa
}

\begin{abstract}
RESUMO - O artigo analisa comentários de professores $(n=414)$, em duas redes sociais, sobre a temática da indisciplina escolar. A abordagem é plurimetodológica, com caráter exploratório-descritivo e procedente análise de conteúdo. Para análise textual dos comentários, utilizou-se o software Alceste, que repartiu o corpus em três classes: classe 1, problemas disciplinares encontrados no cotidiano docente, em sala de aula; classe 2, causas extraescolares para indisciplina; classe 3 , ações coercitivas para reprimir a indisciplina. Pelos comentários, conclui-se que há uma representação social dominante pautada em atitudes defensivas, compreensão heterônoma e explicação exógena ao ambiente escolar e pedagógico, e outra minoritária, de natureza relacional, que leva em consideração a interação dos fatores que a produzem.
\end{abstract}

Palavras-chave: disciplina na sala de aula, interação professor-aluno, formação de professores, escolas, internet, representação social

\section{Social representation of scholl indiscipline}

\begin{abstract}
The article analyzes the commentaries of teachers $(n=414)$ in two social networks on the topic of school indiscipline. The approach is pluri-methodological, with an exploratory-descriptive character based on content analysis. For the textual analysis of commentaries, the software Alceste was employed, which divided the corpus in three classes: Class 1, disciplinary problems encountered in everyday teaching in the classroom; class 2, extracurricular causes of indiscipline; class 3 , coercive actions to curb indiscipline. On the basis of the commentaries the conclusion was made that there is a dominant social representation guided by defensive attitudes, heteronomous understanding and explanation exogenous to the school and educational environment, and another minor one, of relational nature that takes into account the interaction of the factors that produce it.
\end{abstract}

Keywords: classroom discipline, teacher student interaction, teacher education, schools, internet, social representation

A indisciplina escolar, contextualizada em sua rede de relações, expressa as crises e tensões que atravessam a escola em sua historicidade, ultrapassando as explicações de cunho causal (Justo, 2010). É um problema mundial que se expressa e se amplifica em novas nuances nos países mais pobres (Parrat-Dayan, 2008). Nesse contexto, as salas de aula brasileiras são mais indisciplinadas do que a média de outros 66 países avaliados pelo PISA (OECD, 2009). Além disso, a indisciplina é um dos principais elementos que causam desgaste na docência (Carlotto, 2011; Noronha, Assunção, \& Oliveira, 2008; Rosso \& Camargo, 2011).

Por ser a indisciplina fruto de contextos, a multiplicidade causal e interpretativa muda no espaço e no tempo (ParratDayan, 2008), associada ao ponto de vista do observador e intérprete. Como objeto circulante e de relações entre os atores escolares, produz atitudes, imagens e conhecimentos (Moscovici, 2012) que circulam entre as esferas subjetivas, intersubjetivas e transubjetivas (Jodelet, 2009). Por isso, a indisciplina é perceptível nas manifestações sociais, exposta e multiplicada nos meios de comunicação (Parrat-Dayan, 2008). Ultrapassando os limites da escola, chega às instâncias sociais, entre as quais estão a internet e as redes sociais a ela associadas.

1 Endereço para correspondência: Campus de Uvaranas, Av. General Carlos Cavalcanti, 4748, CIPP, sala LP -105, Ponta Grossa, PR, Brasil. CEP 84.030-900.E-mail: adrianoacfuepg@hotmail.com
Por muito tempo, os mass media se limitaram à produção e disseminação unilateral da informação, em um processo no qual um pequeno grupo de instituições controlava a sua propagação. Todavia, com o advento da internet o processo comunicativo se democratizou, servindo como meio de divulgação de informações pessoais. Por meio dela, o sujeitomídia pode expressar suas opiniões, atitudes e informações em redes sociais (Cruz, 2012).

As redes sociais são ambientes virtuais da internet nos quais os sujeitos interagem "instituindo uma forma de sociabilidade" (Dias \& Couto, 2011, p. 636) que se caracteriza pela troca e circulação de informações e pela articulação de vivências comuns entre os participantes (Delazari \& Brandalize, 2012). Nelas o cidadão deixa de ser apenas um receptor passivo de informações para ser também, ele mesmo, um produtor e propagador da informação. De tal modo, as redes sociais oferecem excelentes oportunidades para investigar as representações sociais de grupos, captando as características gerais e particulares dos diferentes grupos participantes.

Nesse contexto, objetiva-se analisar os comentários de professores em duas redes sociais sobre a indisciplina escolar. Busca-se compreender sua manifestação e as discussões que nela circulam sobre o tema. 
As pesquisas sobre a indisciplina destacam carências formativas dos professores e as consequentes confusões conceituais (Huberman, 1995) entre autoridade e autoritarismo (Aquino, 1996b), bem como entre democracia e permissividade (Parrat-Dayan, 2008). Ademais, os docentes mantêm posturas defensivas que restringem a complexidade dessa temática, explicando-a ora pela sociedade, ora pela família (Santos \& Rosso, 2012), ou responsabilizando os próprios alunos (Belém, 2008; Garcia, 2009). Nessas representações, o aluno indisciplinado é o reflexo da sociedade e de sua família ou de algum problema pessoal, mas raramente é articulado aos elementos específicos da relação pedagógica (Estrela, 1992). Nesse sentido, Garcia (2009) identifica três representações docentes associadas à gênese da indisciplina. Na primeira, relativa ao aluno, as explicações oscilam de acordo com os interesses em jogo associados à disputa de poder nas relações escolares, levando a uma permanente luta entre professores e alunos. A segunda resulta do contexto próprio das relações entre os sujeitos que atuam em sala de aula. Por fim, a terceira considera a indisciplina como uma mensagem cultural, na medida em que ela está intrinsecamente relacionada à natureza e à função social da escola.

Assim, as manifestações da indisciplina escolar vêm se transformando nas escolas. Logo, o estudo da sua representação entre os professores que participam das discussões nas redes sociais permite compreender suas transformações com número maior de sujeitos e em espaços mais amplos, que poucas pesquisas sobre o tema conseguem abarcar.

Para captar o pensamento social dos professores internautas apropriou-se, nesta investigação, do aporte teórico-metodológico das Representações Sociais (Moscovici, 2012) e suas abordagens complementares (Menin, 2007; Jodelet, 2009). Para comparar e analisar criticamente esse pensamento social realizou-se a leitura da indisciplina a partir dos postulados defendidos por Piaget (1994) sobre o desenvolvimento moral e de estudos posteriores (Araújo, 1996; La Taille, 1992; Menin \& Zechi, 2010). Na próxima seção, efetua-se a descrição desses referenciais teóricos e da complementaridade entre eles.

\section{Representações Sociais dos Professores: Autonomia ou Heteronomia?}

A representação social é uma forma de conhecimento pela qual as pessoas compreendem e significam a realidade. Ela é fruto de inter-relações de grupos sociais, os quais difundem símbolos, imagens e atitudes análogas e/ou díspares sobre um determinado objeto do cotidiano dos sujeitos. Com isso, a representação social "aponta para o entrelaçamento entre o objeto representado e o sujeito que o representa" (Barros \& Arruda, 2010, p. 353). E mais, ela é um conteúdo mental que é conscientemente partilhado com os demais sujeitos de um grupo social, bem como um processo público "de criação, mudança, elaboração e difusão de conhecimento" (Natividade \& Camargo, 2012, p. 193).

Um pensamento social é considerado uma representação social se estiver constituído pelas dimensões atitude, informação e campo de representação (imagem) (Moscovici, 2012). A atitude enfatiza "a orientação global em relação ao objeto da representação social" (p. 65). A informação refere-se à "organização dos conhecimentos que o grupo possui com respeito ao objeto social" (p. 62). Por fim, a dimensão campo de representação relaciona-se "à ideia de imagem, de modelo social, com conteúdo concreto e limitado das proposições que expressam um aspecto determinado do objeto da representação" (p. 64).

Além das três dimensões, uma representação social pode comportar dois planos distintos: normativo e funcional. $\mathrm{O}$ plano normativo é originário das grandezas socioafetivas, ideológicas ou sociais, isto é, está presente nos ajuizamentos, opiniões e valores admitidos pelo sujeito ou pelo grupo social em que ele está inserido. Esse plano atende à necessidade de os indivíduos saberem como se comportar, como dominar o meio, identificar e resolver os problemas. O plano funcional está associado às características descritivas e à inscrição do objeto nas práticas sociais. São elementos prontamente relacionados à realização das tarefas (Menin, 2007).

Segundo Jodelet (2009), a representação social originase das esferas subjetivas, intersubjetivas e transubjetivas dos sujeitos. A esfera subjetiva está atrelada ao modo como cada sujeito social se apropria e reconstrói as representações de uma maneira singular. Contudo, como o indivíduo não vive num vazio social, essa singularidade comporta condicionantes sociais. Sendo assim, quando os professores lecionam, eles elaboram suas crenças e dúvidas em seu mundo social, reagindo e (re)apresentando, cada um a seu modo, alternativas para superar a indisciplina. Devido a essa esfera subjetiva, as representações sociais não necessitam conter um direcionamento similar, podendo se diferenciar entre os grupos sociais.

É na esfera intersubjetiva que se dá a formação e o estabelecimento de representações partilhadas entre os indivíduos. Assim sendo, no campo das redes sociais, os professores compartilham de situações e vivências que busquem o consenso entre seus pares. Nas redes sociais, essas queixas e preocupações subjetivas dos professores encontram um ambiente propício para a disseminação, debate e questionamentos. A esfera intersubjetiva promove a circulação de informações, a divulgação e influências recíprocas. Outro ambiente vital que atende a esses princípios é a sala dos professores (Jodelet, 2009).

Por sua vez, a esfera transubjetiva perpassa tanto a esfera subjetiva quanto a intersubjetiva. Isto é, a representação social é afetada pelas condições ideológicas e de valores de uma sociedade. Aqui, ela diz respeito ao aparato cultural e ao conjunto de modelos, normas e valores transmitidos socialmente. É um universo simbólico acentuado por pressões impostas pela estrutura social, de poder, e pelas ideologias. São os elementos normativos e de valores que caracterizam uma cultura (Menin, 2007).

Os elementos que perpassam a (in)disciplina são as normas e a sua compreensão e vivência, envolvendo contextos de anomia, heteronomia e autonomia (Piaget, 1994). A anomia implica a ausência de regras, ou seja, é o caso, por exemplo, de uma criança recém-nascida e nas fases iniciais da vida, que não entende as regras da sociedade e não sabe o que deve ou não ser feito (Araújo, 1996). A (in) 
disciplina em sua versão heterônoma se baseia na coação tributária de uma autoridade externa que impõe normas e regras. Aqui o respeito é unilateral, ocorre de fora e é imposto, não há participação ativa do sujeito coagido na construção e observância das regras. Por sua vez, a disciplina entendida como forma de construção do próprio sujeito caracteriza a autonomia. Nesse plano, os sujeitos participam da construção das regras, entendendo o porquê de se agir conforme ou contra as mesmas. Ou seja, as regras são construídas em conjunto e o respeito é mútuo, leva em consideração a perspectiva do outro. A autonomia e descentração promovem o diálogo entre professores e alunos, sem imposições (Piaget, 1994).

Assim, a disciplina assenta-se na justiça e na igualdade se na escola for pensada e debatida com a participação de todos os atores escolares. A escola pode adotar, no seu contexto, projetos de educação moral articulados às vivências dos alunos, favorecendo o desenvolvimento moral dos mesmos (Menin \& Zechi, 2010). Essa aliança se dará a partir do diálogo e respeito entre os pares, para que se construa um ambiente de sujeitos autônomos. Desse modo, para se alcançar a autonomia é imprescindível o convívio em espaços cooperativos que sejam a expressão da justiça e da dignidade (La Taille, 2010).

\section{Método}

A pesquisa tem uma abordagem quanti-qualitativa e de caráter exploratório-descritivo, com análise de conteúdo (Bardin, 1977). Esta se caracteriza como um conjunto de técnicas de tratamento de dados que se utiliza de métodos objetivos e ordenados que descrevem o conteúdo, tendo como finalidade a identificação e interpretação do que se diz sobre determinado assunto.

Quanto aos procedimentos adotados, foram inquiridos dois sites $^{l}$ de redes sociais que continham comentários e textos relacionados à indisciplina, sendo o primeiro da Revista Educação Pública. Nesse site, foram compilados 172 comentários. A Revista Educação Pública, a qual faz parte do Centro de Ciências e Educação Superior à Distância do Estado do Rio de Janeiro (CECIERJ), tem como finalidade instigar a interação entre os educadores a partir de oficinas, discussões, produção e publicação de escritos educativos, científicos ou literários. O seu intuito é promover o debate por meio de uma rede de educadores que contribuam e colaborem uns com os outros, configurando-se, assim, como uma rede social (Revista Educação Pública, 2012). Essa colaboração está mais explicita no campo discutindo, que permite ao sujeito, mediante perguntas e respostas, trocar opiniões e juízos sobre questões educacionais. No caso da pesquisa ora apresentada, a pergunta indutora era: "Como lidar com turmas bagunceiras?".

O segundo site apresentava o texto indutor "A Indisciplina na sala de aula" (Almeida \& Machado, 2007), o qual exibia uma vinheta sobre o cotidiano de um professor e suas dificuldades oriundas da indisciplina discente.

1 Retirados de http://www.educacaopublica.rj.gov.br/discutindo/discutindo.php?cod_per=108; http://www.planetaeducacao.com.br/portal/ artigo.asp? artigo $=733$.
Posteriormente, a indisciplina é conceituada com base em Aquino (1996b) e Rebelo (2011). As autoras finalizam o texto listando ações que podem ajudar a minimizar a indisciplina escolar. O texto está presente no portal Planeta Educação, vinculado à empresa Vitae Futurekids (Planeta Educação, 2012). Dessa página, foram elencados 261 comentários.

Os sites elencados estão disponíveis ao público que o acessa, sem restrições ou prévio cadastro de coleta de informações. Além do mais, não há em nenhum momento alusão aos nomes dos comentadores, das escolas as quais lecionam ou quaisquer menção a dados pessoais no geral.

Foram analisados 414 comentários, dos quais 95 provieram de professores e 319 de professoras. Os comentários $(n=19)$ que não traziam contribuições ao problema da indisciplina escolar foram retirados em atendimento ao requisito de ser um corpus monotemático. A partir disso, as informações foram organizadas para processamento no programa ALCESTE - Analyse Lexicale par Contexte d'un Ensemble de Segments de Texte (Reinert, 1998), o qual possibilita uma análise lexicográfica das informações. Nele, cada comentário constitui uma unidade de contexto inicial (UCI), sendo que as diferentes unidades são marcadas pelo seu vocabulário. O conjunto de UCIs forma um corpus de análise. O corpus de análise contribuinte é dividido pelo programa em classes de vocábulos que indicam as convergências semânticas sobre um determinado tema (Nascimento-Schulze \& Camargo, 2000). O software ainda proporciona unidades de contextos elementares (UCE), que são "segmentos de texto (...) dimensionadas pelo programa informático em função do tamanho do corpus e, em geral, respeitando a pontuação" (Camargo, 2005, p.514).

O ALCESTE atua por meio de quatro etapas. A primeira executa a leitura e sistematização do corpus, reconhecendo e repartindo as UCIs em UCEs. Na segunda fase do processo, acontece o balanço das matrizes de dados, a categorização das UCEs e a classificação hierárquica descendente. Por sua vez, na terceira etapa se constituem as classes, suas relações e a análise fatorial de correspondência. Por fim, a quarta etapa calcula e comporta as UCEs mais características de cada classe, bem como possibilita outros cálculos e recursos (Camargo, 2005).

\section{Resultados e Discussão}

O processamento do corpus Indisciplina pelo ALCESTE apontou para três classes que estão dispostas no dendrograma que apresenta classificação hierárquica descendente na Figura 01. Foram computadas 414 UCIs e 1023 UCEs, tendo o corpus um aproveitamento de $76,15 \%$ das análises processadas. Para a apresentação das classes, foi considerada a frequência mínima de quatro palavras e o qui-quadrado $\left(X^{2}\right) \geq 11,52$, valor três vezes maior que o mínimo indicado de 3,84 . Essas classes indicam três focos de discussão sobre a indisciplina presentes no corpus.

A apresentação das classes será realizada de acordo com as associações e as partições textuais efetuadas pelo programa. Dessa forma, serão expostas inicialmente as classes associadas 1 e 3 - dificuldades disciplinares e ações disciplinares - seguidas da classe 2 , justificativas externas. 


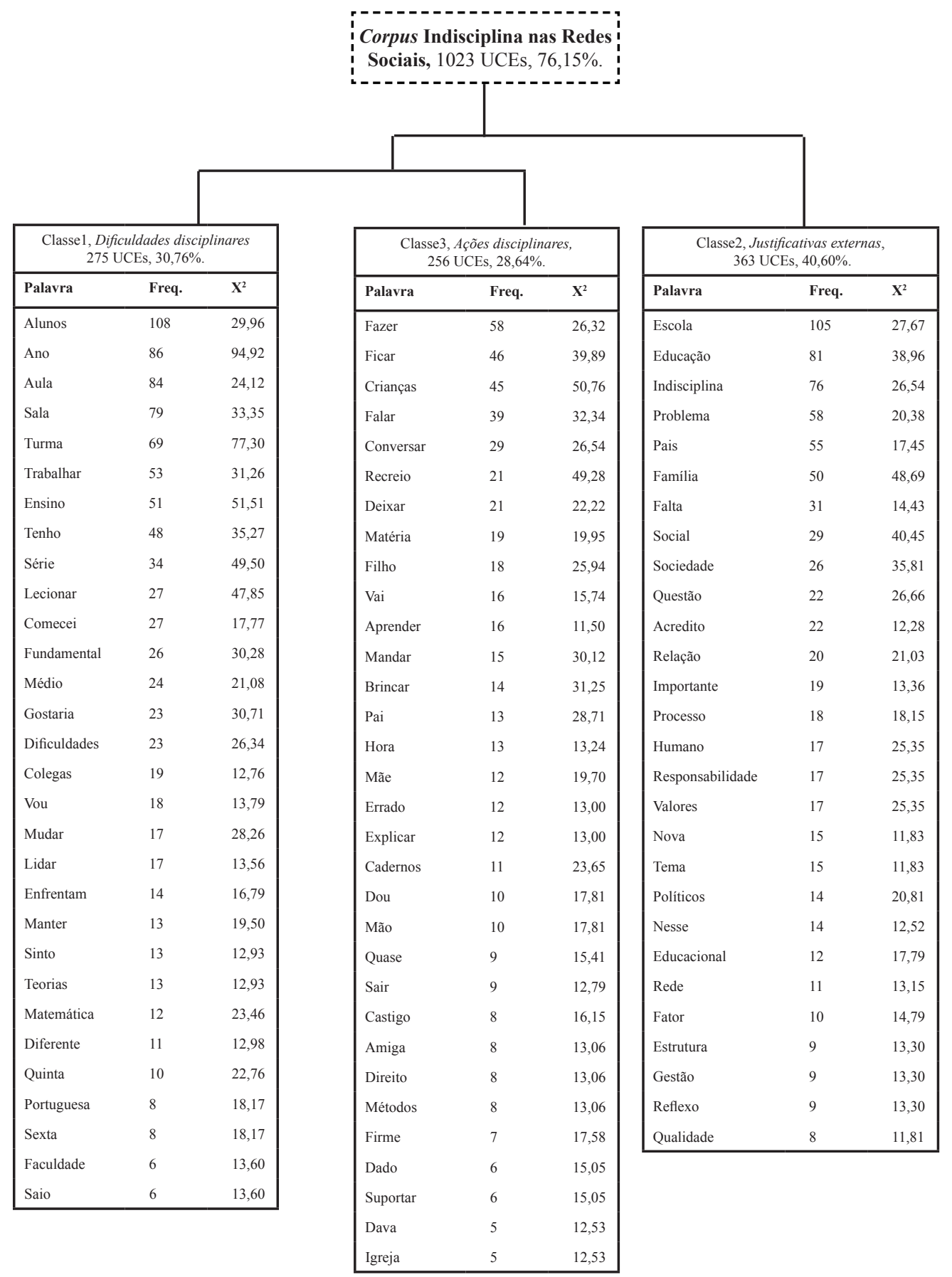

Figura 1. Dendrograma da classificação hierárquica descente do corpus indisciplina

A classe 1, dificuldades disciplinares, contempla $30,76 \%$ das informações analisadas. Essa classe recebeu uma contribuição significativa dos informantes do gênero feminino e dos participantes do site 2, o qual apresentava um texto motivando a participação dos sujeitos. Alguns termos presentes no dendrograma possibilitam deduzir as características dessa classe: turma, ensino, série, lecionar, alunos, aula, sala, fundamental e médio. Tudo indica que são situações funcionais do contexto da sala de aula, nos diversos níveis de ensino. Pelas palavras comecei, lecionar e dificuldades, pode-se constatar que os informantes são professores/as iniciantes que encontram maiores dificuldades em relação à indisciplina escolar e que elencam algumas experiências vividas em seu cotidiano. Denotam, assim, níveis descritivos e funcionais da representação, a qual é constituída pelos elementos da ação operacional docente em sala de aula, como consta nos comentários apresentados a seguir: 
Estou começando a trabalhar na sala de aula agora, e estou com uma tremenda dificuldade, pois estou com um sexto ano onde a maioria é repetente.

Gostaria de umas dicas para manter a sala com disciplina, porque estou dando aula no ensino médio e estou encontrando dificuldades de manter a sala em ordem principalmente o primeiro ano.

Comecei a lecionar em uma escola com turma de quarenta e três alunos do sexto e oitavo ano, com alunos bagunceiros. A direção da escola me acusa de não estar impondo ordem na sala, e tudo indica que vou ser expulsa.

Pelas expressões docentes, nota-se que a indisciplina escolar se apresenta como um desafio ao professor iniciante (Souza, 2005), marcado pela sobrevivência e descoberta (Huberman, 1995). Na vivência do complexo e do inesperado, o professor "percebe a distância entre os seus ideais educacionais", cultivados no espaço formativo, e a "vida cotidiana nas escolas" (Leone \& Leite, 2011, p. 240). A descoberta de pertencer ao grupo e a sensação de experimentar-se professor associam-se às problemáticas vivenciadas e seus futuros desdobramentos. Essa é uma das situações que mais dificulta e desgasta os professores iniciantes em sala de aula. Suas dificuldades indicam as lacunas de uma formação inicial que não os habilita para o enfrentamento da situação, por isso eles clamam por "ajuda" para resolver os problemas disciplinares. Sua carência formativa torna a inserção profissional mais difícil e complicada, justificando-se assim "um conjunto de demandas formativas para os processos de formação contínua" (p. 242). Resta aos docentes iniciantes enfrentarem a indisciplina a partir de seus conhecimentos adquiridos no cotidiano escolar; e não mediante o estudo de referenciais teóricos sobre ela.

A classe 3, ações disciplinares, contém 28,64\% das informações do corpus, recebendo tributo diferenciado do site 1 e dos informantes do gênero feminino. Os sujeitos que se sobressaem na classe são crianças, filho e amiga, referindo-se aos termos recreio, firme, hora, e direito. Os verbos indicados sãoficar, mandar, conversar, fazer, brincar, deixar, suportar, explicar, sair e aprender. Os segmentos de texto abaixo contextualizam essas informações da classe:

Eu procuro deixá-los sem recreio, digo que, enquanto não aprenderem que não estão em casa, ficarão sem recreio. Mando fazer exercicios extras em casa pedindo a assinatura dos responsáveis e procuro ser amiga deles, porém, com pulso firme. $O$ negócio é ter pulso firme para olhar para uma pessoa e falar a verdade com ela, isso ajudará a pessoa a pensar bem nos seus atos.

Temos regras para ser cumpridas. A criança também tem que aprender as regras. Ela já fica em casa brincando. A escola é lugar de aprender, aprontou vai ficar sem recreio sim.

Os comentários dessa classe desvelam docentes com ações coercitivas, impondo-se regras e normas de modo verticalizado. Além do mais, são feitas chantagens aos alunos, como deixar sem recreio e punições severas, sem esquecer-se do "pulso firme". Com isso, constitui-se o respeito unilateral da regra, já que ela é "considerada como sagrada e produz no espírito da criança sentimentos análogos àqueles que caracterizam o conformismo obrigatório das sociedades inferiores" (Piaget, 1994, p. 270). Entretanto, se essa prática coercitiva permanecer exclusiva, poderá favorecer a heteronomia dos discentes, mantendo-os sempre dependentes de fontes de controle externo (La Taille, 1992).

Nesse sentido, os professores, cada um ao seu modo, seja por meio de experiências domésticas ou por traços de personalidade, procuram a solução da indisciplina de modo pragmático. Esse pragmatismo carente de reflexão pode patrocinar iniciativas heterônomas dos professores, dificultando o desenvolvimento da autonomia moral dos alunos, visto que não favorecem experiências de respeito mútuo e cooperação pelas regras sociais, já que elas são dadas de antemão, em um todo pronto e acabado (Piaget, 1994).

No geral, os comentários da classe docente denotam a negação da responsabilidade sobre o problema disciplinar e atribuem a "culpa" à turma ou às características individuais dos alunos (Santos \& Rosso, 2012). Mas, como uma particularidade pouco frequente, e na contramão dessa tendência, destacam-se comentários que consideram que as questões pedagógicas e as políticas educacionais específicas da escola favorecem a emergência de manifestações de indisciplina. São comentários que expressam adesão ao texto do site 2 .

Nesses comentários, os professores concebem a indisciplina enquanto relações dos atores e contextos escolares; ou, ainda, enquanto uma manifestação típica do ambiente social, que carrega uma mensagem cultural. Tal como Garcia (2009) salientou, são posicionamentos que contrastam com os discursos de teor defensivo e vitimizante. Agora os professores são corresponsáveis e assumem outras atitudes ante a indisciplina. Os comentários a seguir contextualizam essas informações:

É de suma importância para se refletir com professores na busca de soluções para os problemas disciplinares.

É preciso chamar, além dos professores, a responsabilidade de todos os demais agentes pedagógicos envolvidos no processo e na antropogênese da indisciplina.

Por fim, a classe 2, justificativas externas, apresentou $40,60 \%$ do total das informações analisadas e recebeu contribuições diferenciadas do gênero masculino e do site 2. O campo das justificativas é permeado pela tentativa de responder à indagação que se fez sobre o que torna os alunos indisciplinados. De tal modo, para os informantes, as causas da indisciplina estão relacionadas aos seguintes fatores: familia, pais, social, sociedade, valores (a ausência desses), políticos, (sistema) educacional, profissionais (professores), escola, legislação, políticos, educação (falta) e estrutura.

A partir da frequência e dos valores de $\mathrm{X}^{2}$ do dendrograma, destacam-se as causas da indisciplina atribuídas a questões familiares, políticas, sociais e econômicas. Os termos que destacam os elementos pedagógicos são raros, dando a impressão de que a escola simplesmente é o reflexo da sociedade, indicando uma ancoragem em teorias reprodutivistas (Bourdieu \& Passeron, 2009), afirmando que nada se pode mudar na escola, se não houver mudanças estruturais e sociais. As mudanças sociais contemporâneas - a inserção da mulher no mercado de trabalho, novas tecnologias, globalização e outras situações - acabam justificando conflitos e contingências próprios do ambiente escolar.

Nota-se, em seus comentários, que os professores procuram no seio familiar razões para as características 
negativas dos alunos. Nesse sentido, eles esperam e desejam encontrar na escola pública filhos de famílias participativas e estruturadas, ou seja, um aluno ideal proveniente de uma família ideal (Alves-Mazzotti, 2006), ideologicamente segundo "os padrões familiares dominantes" (Barreto, 1980, p. 48). Visto que, para esses docentes, a indisciplina está associada à desestrutura familiar e ao baixo nível socioeconômico dos alunos, eles apontam "os padrões de comportamento familiar de um grupo que não é o seu apenas como fruto de uma deformação moral" (Barreto, 1986, p. 307). Com isso, o professor mostra-se encerrado no seu moralismo rígido. É a educação bancária: aos professores cabe ensinar os conteúdos escolares; e à família, a formação moral e a educação dos filhos nos padrões sociais das classes dominantes (Rebelo, 2011). Tais pressupostos destoam dos princípios genéticos que conduzem os sujeitos à autonomia moral (Piaget, 1994), que se processa em todas as instâncias e relações sociais qualitativamente distintas de cooperação. Assim, o desenvolvimento moral não é responsabilidade apenas da família, e, desse modo, a escola pode contribuir significativamente para que ele aconteça, mediante a promoção de um ambiente cooperativo e democrático (ParratDayan, 2008).

Nesse contexto, se, para a escola, a criança é o aluno que precisa fazer atividades, provas, tarefas e outros trabalhos; para os pais, é o filho, objeto de preocupações imediatas como alimentação, saúde e vestimenta (Varani \& Silva, 2010). Apesar de preocupações diferentes, é imperativo escola e família unirem empenhos nessa tarefa comum. Todavia, quando a família não pode prover algumas necessidades formativas e emocionais básicas dos filhos, a escola não pode virar as costas e excluí-los (Reis, 2008).

Em síntese, as justificativas dos professores para as turmas bagunceiras indicam causas estruturais que os isentam de responsabilidades, tornando-os apenas as vítimas da indisciplina. Assim, para os docentes as causas e algumas soluções para a indisciplina passam por ações e/ou reflexões, tais como:

A família não está preocupada com a qualidade de ensino, mas se o tempo do aluno está sendo preenchido com alguma coisa. $A$ verdade é que a incivilidade e a indisciplina estão tomando conta da educação e, infelizmente, a escola não poderá sozinha reverter esse quadro porque ela não pode tomar o lugar da família na educação dos alunos.

Onde as selvagens leis de mercado são imperativas e o estado se torna, cada vez mais, mínimo. [...] A escola é um dos reflexos da crise da sociedade, dos valores, da família e das relações sociais de produção.

São várias as causas da indisciplina, mas a principal delas é a formação familiar, que está sendo guiada pelos meios de comunicação de massa, por consequência, os pais são facilmente influenciados pelas imposições da mídia, que dita regras e valores comportamentais, ou seja, os pais educam os filhos segundo suas necessidades.

$\mathrm{O}$ quadro geral do conteúdo das classes provenientes dos comentários postados permite a identificação de duas tendências de respostas, denominadas causal e relacional, e a presença da variável gênero. Por isso, buscou-se ampliar a análise fazendo a comparação não só entre as tendências causal e relacional, como também entre os gêneros masculino e feminino, a fim de destacar as especificidades e as diferenças por meio da análise tri-croisé. Mediante essa análise, torna-se possível isolar determinada categoria, tema ou variável para efetuar o cruzamento de seus dados em relação às demais categorias (Paredes \& Kawahara, 2000).

Do total de 414 comentários, 166 (40,1\%) provêm do site 1 e $248(59,9 \%)$ do site $2 ; 95$ (22,9\%) provêm do gênero masculino e $329(77,1 \%)$, do gênero feminino. Quanto às posições expressas nos comentários, 324 (78,3\%) são identificadas como posicionamento causal e $90(21,7 \%)$, como posicionamento relacional. A síntese das informações cruzadas em relação aos sites e ao sexo, considerando os posicionamentos expressos, foi obtida com o auxílio do programa SPSS Statistics $17.0^{2}$, por meio da operação estatística Crosstab (tabela de referência cruzada) e consta da Tabela 01. Essas informações indicam que os diferentes formatos dos sites não interferem nas orientações dos comentários, mas o sexo dos informantes determina uma discreta contribuição do sexo masculino na expressão do posicionamento relacional.

2 O SPSS é um programa de análise estatística e manuseamento de dados, num ambiente gráfico (Ferreira, 1999).

Tabela 01. Síntese das informações em função dos sites e do sexo

\begin{tabular}{clccccc}
\hline & & \multicolumn{5}{c}{ Posicionamento } \\
\hline & Variável & \multicolumn{3}{c}{ Causal } & \multicolumn{3}{c}{ Relacional } & \\
\hline \multirow{2}{*}{ Site } & Freq. & \% & Freq. & \% & X2 \\
& Site 1 & 131 & 78,9 & 35 & 21,1 & \multirow{6}{*}{ Sexo } \\
& Site 2 & 193 & 77,8 & 55 & 22,2 & 0,070 \\
& Masculino & 66 & 69,5 & 29 & 30,5 & \\
& Feminino & 258 & 80,9 & 61 & 19,1 & 5,596 \\
\hline
\end{tabular}

Os subgrupos que constam na Tabela 01 podem fornecer diferentes visões da indisciplina escolar. Convém observar que as porcentagens apresentadas a seguir diferem das porcentagens indicadas na Tabela 01 , referindo-se à quantidade de produções textuais e não ao total de informantes. Com isso, a análise tri-croisé busca fornecer subsídios para ampliar as discussões das variáveis: sexo feminino contendo $74,3 \%$ das informações e sexo masculino contendo $25,6 \%$; posição causal com $72,6 \%$ das informações e posição relacional com $27,3 \%$. As variáveis que se mostraram mais discordantes com a maioria são, portanto, $o$ sexo masculino e a posição relacional. Os professores tendem a apresentar aspectos mais gerais e estruturais, enquanto as professoras priorizam situações causais e pontuais. Com isso, há o indicativo de que as professoras se ressentem mais com os problemas disciplinares e tendem a expressá-los em termos de causalidade e com ligações a aspectos domésticofamiliares. É uma visão ancorada em uma concepção sexista da sociedade, que concebe a mulher ligada à figura materna, com características de fragilidade, docilidade e proteção (Souza, 2006). Por outro lado, os professores parecem se ressentir menos e expressam a indisciplina em termos relacionais e voltados para o espaço social. Essa diferenciação já foi apontada por Rosso e Camargo (2013) sobre o desgaste na docência. 
Os professores tendem a destacar mais discretamente as situações de corresponsabilidade, associando-as aos aspectos políticos, econômicos, sociais e familiares, entre outros. Segundo essa visão, para as ações pedagógicas serem bem-sucedidas, há necessidade de se compreender as conjunturas da ordem macrossocial. Já para a tendência que recebe a contribuição diferencial e discreta das professoras sobre as explicações da indisciplina, encontram-se questões funcionais e familiares. As causas estão intramuros da escola ou do ambiente doméstico associado a correções de comportamentos desviantes. Dessa maneira, há uma tendência de as professoras associarem mais as ações de indisciplina a fatores microssociais, e de os professores as associarem a conjunturas macrossociais, mas ambas as situações ignoram os aspectos pedagógicos.

A escola é majoritariamente um ambiente feminino, seja na posição de professoras ou de alunas (Abramovay, Cunha, \& Calaf, 2009) e nela encontra-se, subliminarmente, uma "hierarquia de valores em que o feminino é melhor do que o masculino" (Rodrigues \& Mazzotti, 2013, p. 54). Dessa maneira, as mulheres estariam "mais adaptadas à escola contemporânea, em que o processo de socialização feminino orienta-se para a passividade e obediência às normas" (p. 46), e qualquer atitude em contrário é tida como comportamento desviante, indisciplina.

$\mathrm{Na}$ análise efetuada com o auxílio do ALCESTE, predominaram os conhecimentos sobre a indisciplina escolar. Por sua vez, entremeando os comentários, emergem os planos atitudinais e imagéticos (campo de representação) como dimensões complementares para captar a representação da indisciplina circulante nessas redes sociais (Natividade \& Camargo, 2012).

As atitudes dos docentes em relação à indisciplina denotam a impotência, a desvalorização e o sentimento de fracasso do professor frente aos alunos, expressos em frases como "não saber mais o que fazer"; "é muito complicado para lecionar com turmas bagunceiras"; "sinto-me impotente e muito angustiada"; "estou me sentindo uma fracassada". Aparece, ainda, a desvalorização salarial e simbólica como contingência no trabalho docente: "Se a profissão fosse valorizada e pagasse melhor, nosso trabalho seria desenvolvido com mais qualidade".

Os comentários emitidos manifestam atitudes coercitivas, com ameaças mais contundentes para controlar os alunos: "Ameacei alguns de chamar o conselho tutelar". Ou afirmam que é necessário "garantir uma punição mais severa onde o aluno pode ficar na escola no contra turno ou no sábado", ressaltando, também, que os alunos indisciplinados "ficarão sem recreio". Com isso, esses professores parecem reagir à indisciplina dos alunos condenando-os unilateralmente. Também aparecem negações das teorias científicas, que "não são aplicáveis em sala de aula", sendo chamadas de "fantasiosas". E, o mais impressionante, chegou-se a afirmar que a "única teoria certa mesmo, é a de Pinochet" (e diríamos, para rimar, não a de Piaget!).

Por outro lado, há a desistência de pensar o problema, através da vitimização: "o problema da bagunça (...) mais uma vez, o professor é o vilão". Além disso, perante a complexidade e as dificuldades para o entendimento da indisciplina, os docentes recorrem à ajuda divina: "Só posso recorrer à fé em Deus e pedir a ele sabedoria para enfrentar os desafios diários"; e ainda entregam o problema "nas mãos de Deus e seja feita a vontade dele". Isso significa renúncia e esperança de que ocorra um milagre. Mais uma vez, tais atitudes sugerem carências formativas (Ramalho \& Núñez, 2011), já que se encara a indisciplina somente a partir da experiência cotidiana, da busca pessoal e não da ciência.

$\mathrm{Na}$ contramão, em meio à descrença e à desistência, aparecem atitudes reflexivas e esperançosas que podem ser o prenúncio para a compreensão da problemática, como, por exemplo, "conhecer essas crianças (alunos), o contexto familiar e social delas, para então traçarmos um plano de ação", sem tratar as crianças "como se fossem delinquentes que tem o banho de sol cancelado por indisciplina". Aqui, os docentes expressam a busca por uma nova forma de relacionamento com os alunos, baseada em princípios dialógicos para a prevenção e remediação da indisciplina escolar, com especial atenção para a afetividade, a conversa, a busca pela igualdade e por experiências de reciprocidade junto aos educandos (La Taille, 2010).

No contexto dos comentários, surgem ainda imagens acerca da indisciplina, é a dimensão campo de representação. Para os professores, há uma relação temporal, que nega o presente, com comentários do tipo "antigamente o ensino era melhor", "hoje o aluno tem muita liberdade"; "se fosse como tempos atrás, talvez a criança tivesse limites"; e ainda "as escolas antigas funcionavam melhor porque havia a punição". Novamente as punições aparecem como forma de manter a disciplina. Essa "escola de antigamente" remete a um tempo de disciplina "imposta à base do castigo ou da ameaça" (Aquino, 1996b, p. 43), em que professores e alunos portavam papéis bem definidos: "o primeiro, um general de papel; o segundo, um soldadinho de chumbo" (p. 43). Em suma, é a imagem de uma escola delineada pelo medo, coação e subserviência.

Aparecem mais imagens sobre os alunos como "bando de bagunceiros", "sala de loucos", "crianças vazias de sonhos", "donos da galáxia" "filhos malcriados" ou "bando de alunos que não querem nada com a vida". Tais imagens ilustram a geopolítica imaginária que cerca as relações escolares, "imbuindo e esquadrinhando a ocupação dos lugares instituídos de docentes e discentes", levando a um permanente campo de lutas entre esses atores escolares (Aquino, 1996a, p. 156). Nessa geopolítica, "aluno e professor enfrentam-se (...) como inimigos potenciais e estão na defensiva" (Parrat-Dayan, 2008, p. 26).

Duas imagens trazidas pelos professores são representativas desse quadro. São comparações do trabalho docente a dois episódios: episódio mitológico (Atlas) e episódio bíblico (profeta Daniel). O primeiro carrega "o mundo nas costas"; e o segundo é "jogado na cova dos leões". No primeiro caso, uma informante apresenta o seguinte comentário: "Estou tão cansada que parece que carrego o mundo nas costas". Esse fardo se assemelha às imagens destacadas por alguns professores que sentem carregar não só a indisciplina, como também as contingências do trabalho, sociedade e família nas costas. Isso porque se carrega o ônus de disciplinar os alunos para a aprendizagem, as relações interpessoais e as adversidades da docência, ou seja, carrega-se o mundo. No segundo caso, do profeta 
Daniel, jogado injustamente à cova dos leões pelo rei Dario, escreveu um sujeito: "No início sentia-me como aquele rapaz da bíblia que foi jogado aos leões". Nessa imagem, os professores se julgam injustiçados por ser atribuída a eles parte da responsabilidade pela indisciplina. Continuam os comentários: "Cheguei à educação com ideias e projetos. Quando menos espero, sou enclausurado dentro de uma jaula com animais sociais". No caso de Daniel, a situação para ele se inverte, pois o anjo de seu Deus tranca a boca dos leões. Daniel é libertado pelo rei e seus delatores é que são entregues para serem devorados pelos leões.

Contudo, o que mais se destaca dessas imagens sobre a indisciplina é a impotência dos professores, visto que "(estão) de mãos e pés amarrados". Isto é, os docentes, perante o contexto de indisciplina escolar, sentem-se tolhidos, sem condições de exercer seu papel pedagógico em sala de aula.

\section{Considerações Finais}

Os comentários postados pelos professores nas redes sociais demonstram as suas inquietações frente aos problemas disciplinares da escola e a necessidade de discuti-los. Além de exibirem angústia e inquietação, esses indicativos constituem uma das matrizes formadoras e de circulação de representações sociais. Em seus comentários, os professores se desdobram em explicações que circulam entre a sala de aula, as estratégias de controle e os espaços extraescolares.

Nesses deslocamentos, predominam as atitudes defensivas, evasivas e de vitimização, atribuindo a indisciplina a causas familiares e sociais, encontrando-se em segundo plano as atitudes reflexivas que buscam a contextualização do problema. As imagens recolhidas estão alinhadas a essas atitudes, apontando para quadros dramáticos extremos de paralisia, castigo ou injustiça, solúveis mediante forças sobrenaturais. Os conhecimentos que perpassam os depoimentos dos professores pesquisados são porta-vozes de espaços e experiências imersos em um quadro, dominante, de heteronomia e outro, minoritário, como uma fissura, para as relações disciplinares fundadas na autonomia.

$\mathrm{O}$ ordenamento das atitudes, imagens e conhecimentos indica duas representações sociais polarizadas sobre a indisciplina: a principal e dominante, de natureza causal; e outra secundária, de natureza relacional. A síntese delas pode advir na interpretação da afirmação de Sartre (2011), "o inferno são os outros"! A sua compreensão apoia-se na liberdade e responsabilidade pessoal, nas relações interpessoais. No lado majoritário, estão as relações assimétricas, expressas em coerções, ameaças, castigos, chantagens e punições, que geram estranhamento, defensas e denegações; e, no lado oposto, estão as relações simétricas, no reconhecimento e afirmação, gerando cooperação, diálogo, descentração, altruísmo e alteridade. Assim, a indisciplina, em sua perspectiva causal, é um inferno de sofrimentos e ranger de dentes, advindo dos outros, atribuído aos outros; contudo, numa perspectiva relacional não ocorre essa transferência e o inferno somos nós. No segundo caso, estamos juntos diante de uma possibilidade educativa e somos parte da sua transformação.
De acordo com a representação principal, a indisciplina não pode ser solucionada enquanto a família não participar e a sociedade não se transformar, pois " a sala de aula é um reflexo da sociedade" e o "nosso papel é ensinar, o papel de educar é da família". Nessa representação, só resta clamar: "Por favor, me dê alguma esperança para continuar"! Porém, contrastam com essa representação hegemônica os comentários de natureza relacional, como: "O respeito é a base das relações sadias"; "o professor tem uma parcela da responsabilidade, assim como a família, a sociedade, o governo", ou seja, "toda a sociedade (necessita atuar) para resolver (...) os problemas educacionais"; o ensino necessita de "conteúdos críticos e sociais contextualizados".

Assim, o professor não "carrega" sozinho o ônus disciplinar, como um "atlas" carrega o mundo, nem o atribui a outrem; tampouco é devorado por "leões", ou resgatado milagrosamente. Mas dada sua complexidade, o enfrentamento da indisciplina integra melhores condições de trabalho, investimento na educação e parcerias entre governo, comunidade, família e escola, bem como uma sólida formação docente, a promoção de espaços cooperativos e democráticos nas escolas. Apesar de a indisciplina estar relacionada a múltiplos fatores internos e externos à escola, ao professor cabe integrar e dialogar com eles no contexto pedagógico, na docência. Dessa forma, apesar de minoritária, para a representação relacional, o inferno da indisciplina somos nós.

\section{Referências}

Abramovay, M., Cunha, A. L., \& Calaf, P. P. (2009). Revelando tramas, descobrindo segredos: Violência e convivência nas escolas. Brasília: Rede de Informação Tecnológica Latinoamericana - RITLA, Secretaria de Estado de Educação do Distrito Federal - SEEDF.

Almeida, S. C., \& Machado, S. (2007). Indisciplina na sala de aula. Retirado em 10 de agosto, 2012, de http://www. planetaeducacao.com.br/portal/artigo.asp? artigo $=733$.

Alves-Mazzotti, A. J. (2006). O "aluno da escola pública”: O que dizem as professoras. Revista Brasileira de Estudos Pedagógicos, 87(217), 349-359.

Aquino, J. G. (1996a). Confrontos na sala de aula: Uma leitura institucional da relação professor-aluno. São Paulo: Summus.

Aquino, J. G. (1996b). A desordem na relação professor-aluno: indisciplina, moralidade e conhecimento. In J. L. Aquino (Org.), Indisciplina na escola: Alternativas teóricas e práticas (pp. 39-55). São Paulo: Summus.

Araújo, U. F. (1996). Moralidade e indisciplina: uma leitura possível a partir do referencial piagetiano. São Paulo: Summus.

Bardin, L. (1977). Análise de conteúdo. Lisboa: Edições 70.

Barreto, E. S. de. S. (1980). A professora primária frente a alunos $e$ alunas de distinta condição social (Unpublished master's thesis), Faculdade de Filosofia, Letras e Ciências Humanas da Universidade de São Paulo, São Paulo.

Barreto, E. S. de. S. (1986). Professores de periferia: soluções simples para problemas complexos. In M. H. S. Patto (Org.), Introdução a Psicologia escolar (pp. 296-319). São Paulo: Editora T. A. Queiroz. 
Barros, C. F. P., \& Arruda, A. M. S. (2010). Afetos e representações sociais: Contribuições de um diálogo transdisciplinar. Psicologia: Teoria e Pesquisa, 26(2), 351-360.

Belém, R. C. (2008) Representações sociais sobre indisciplina escolar no ensino médio. Dissertação de Mestrado, Universidade Federal de Pernambuco, Recife.

Bourdieu, P., \& Passeron, J-C. (2009). A reprodução: Elementos para uma teoria do sistema de ensino. Rio de Janeiro: Vozes.

Camargo, B. V. (2005). ALCESTE: um programa informático de análise quantitativa de dados textuais. In A. S. P. Moreira, B. V. Camargo, J. C. Jesuino, \& S. M. da Nóbrega (Orgs.), Perspectivas teórico-metodológicas em representações sociais (pp. 511-539). João Pessoa: Universitária - UFPB.

Carlotto, M. S. (2011). Síndrome de burnout em professores: Prevalência e fatores associados. Psicologia: Teoria e Pesquisa, 27(4), 403-410.

Cruz, R. do C. (2012). Preconceito social na Internet: A reprodução de preconceitos e desigualdades sociais a partir da análise de sites de redes sociais. Perspectivas em Ciência da Informação, 17(3), 121-136.

Delazari, L. S., \& Brandalize, M. C. B. (2012). Análise de redes sociais a partir do uso da informação espacial. Boletim de Ciências Geodésicas, 18(2), 185-202.

Dias, C., \& Couto, O. F. (2011). As redes sociais na divulgação e formação do sujeito do conhecimento: Compartilhamento e produção através da circulação de ideias. Linguagem em (Dis) curso, 11(3), 631-648.

Estrela, M. T. (1992). Relação pedagógica, disciplina e indisciplina na aula (3a ed). Porto: Porto Codex.

Ferreira, A. M. (1999). SPSS: Manual de utilização. Castelo Branco, Portugal: Escola Superior Agrária de Castelo Branco.

Garcia, J. (2009). Representações dos professores sobre indisciplina escolar. Educação, 34(2), 311-324.

Huberman, M. (1995). O ciclo de vida profissional dos professores. In A. Nóvoa (Org.), Vidas de professores (pp. 31-59). Porto: Editora Porto.

Jodelet, D. (2009). O movimento de retorno ao sujeito e a abordagem das representações sociais. Sociedade e Estado, 24(3), 679-712.

Justo, J. S. (2010). Escola no epicentro da crise social. In Y. de. La Taille., N. Pedro-Silva., \& J. S. Justo (Orgs.), Indisciplina/ disciplina: Ética, moral e ação do professor (3a ed., pp. 23-54). Porto Alegre: Mediação.

La Taille, Y. (1992). Piaget, Vygotsky e Wallon: Teorias psicogenéticas em discussão. São Paulo: Summus.

La Taille, Y. (2010). A escola e os valores: A ação do professor. In Y. de. La Taille., N. Pedro-Silva., \& J. S. Justo (Orgs.), Indisciplina/disciplina: Ética, moral e ação do professor. (3a ed., pp. 5-21). Porto Alegre: Mediação.

Leone, N. M., \& Leite, Y. U. F. (2011). O início da carreira docente: Implicações à formação inicial de professores. Revista Eletrônica Pesquiseduca, 3(6), 236-259.

Menin, M. S. de. S. (2007). O aspecto normativo das representações sociais: Comparando concepções. Revista de Educação Pública, 16(30), 121-135.

Menin, M. S. de. S., \& Zechi, J. A. M. (2010, Setembro). Educação moral em escolas públicas brasileiras: Temas, meios, finalidades e mudanças. Anais do Seminário de Direitos Humanos no Século XXI, $6^{\circ}$ Encontro de Direitos Humanos da UNESP, 4 (p. 1-10). Marília: FFC/UNESP.
Moscovici, S. (2012). A psicanálise, sua imagem e seu público. Petrópolis: Vozes.

Nascimento-Schulze, C. M., \& Camargo, B. V. (2000). Psicologia social, representações sociais e métodos. Temas em Psicologia da SBP, 8(3), 287-299.

Natividade, J. C., \& Camargo, B. V. (2012). Elementos da representação social da Aids agrupados em dimensões: Uma técnica estrutural. Psicologia: Teoria e Pesquisa, 28(2), 193195.

Noronha, M. M. B., Assunção, A. A., \& Oliveira, D. A. (2008). O sofrimento no trabalho docente: $\mathrm{O}$ caso das professoras da rede pública de Montes Claros, Minas Gerais. Trabalho, Educação e Saúde, 6(1), 65-85.

OECD - Organisation for Economic Co-Operation And Development. (2009). Creating effective teaching and learning environments: First results from TALIS. Paris. Retirado em 12 de agosto, 2012, de http://www.oecd.org/ dataoecd/17/51/43023606.pdf.

Paredes, E. C., \& Kawahara, L. S. I. (2000). O uso do software Alceste e a análise tri-croisé em uma pesquisa acerca de representações sociais de caráter transgeracional. Revista de Educação Pública, 9(16), 149-164.

Parrat-Dayan, S. (2008). Como enfrentar a indisciplina na escola. São Paulo: Contexto.

Piaget, J. (1994). O juizo moral na criança. São Paulo: Summus.

Planeta Educação. (2012). Quem somos, a abordagem educacional. Retirado em 10 de agosto, 2012, de http://www.planetaeducacao. com.br/portal/quemsomos.asp.

Ramalho, B. L., \& Núñez, I. B. (2011). Diagnóstico das necessidades formativas de professores do ensino médio no contexto das reformas curriculares. Revista Educação em Questão, 40(26), 69-96.

Rebelo, R. A. A. (2011). Indisciplina escolar: Causas e sujeitos - A educação problematizadora como proposta real de superação. Petrópolis: Vozes.

Reinert, M. (1998). Alceste: Analyse de données textuelles. Manuel d'utilisteur. Toulouse: Image.

Reis, M. P. I. F. C. P. (2008). A relação entre pais e professores: Uma construção de proximidade para uma escola de sucesso (Unpublished doctoral dissertation), E.S.E. João de Deus, Universidade de Málaga, Málaga.

Revista Educação Pública. (2012). Sobre a revista. Retirado em 10 de agosto, 2012, de http://www.educacaopublica.rj.gov. br/sobre.html.

Rodrigues; C. A. G., \& Mazzotti, T. B. (2013). Representação social de gênero no fracasso escolar de meninos. Revista de Educação Pública, 22(48), 45-59.

Rosso, A. J., \& Camargo, B. V. (2011). As representações sociais das condições de trabalho que causam desgaste aos professores estaduais paranaenses. ETD - Educação Temática Digital, 13(1), 269-289.

Rosso, A. J., \& Camargo, B. V. (2013). As representações sociais do desgaste no trabalho a partir dos simbolismos associados à docência. ETD - Educação Temática Digital, 15(1), 179-200.

Santos, E. R., \& Rosso, A. J. (2012). A indisciplina escolar nas representações sociais de professores paranaenses. Psicologia da Educação, 34, 127-157.

Sartre, J-P. (2011). Entre Quatro Paredes. São Paulo: Civilização Brasileira. 
Souza, D. B. (2005). Representações sociais sobre indisciplina em sala de aula dos professores em inicio de carreira da rede municipal de presidente prudente - SP: Implicações para a formação inicial (Unpublished master's thesis), Universidade Estadual Paulista (UNESP), Campus de Presidente Prudente, São Paulo.
Souza, S. D. (2006). Gênero e religião no Brasil: Ensaios feministas. São Paulo: Universidade Metodista de São Paulo.

Varani, A., \& Silva, D. C. (2010). A relação família-escola: implicações no desempenho escolar dos alunos dos anos iniciais do ensino fundamental. Revista Brasileira de Estudos Pedagógicos, 91(229), 511-527. 